\title{
Oat-cell carcinoma of the oesophagus: a recently recognized entity
}

\author{
M. G. COOK, V. EUSEBI, AND C. M. BETTS
}

From the Institute of Pathology, The London Hospital, London E1, England, and Istituto di Anatomia e Istologia Patologica, Universita di Bologna, Italy

SYNOPSIS A primary oat-cell carcinoma of the oesophagus is described with an adjacent squamous iु carcinoma, both parts having characteristic ultrastructure. The origin of this mixed tumour is $\vec{N}$ discussed together with the literature on oesophageal carcinomas having an oat-cell pattern.

The distinctive appearance of oat-cell carcinoma of the bronchus was described by Azzopardi (1959) and Bensch et al (1968) but, as far as we know, only four acceptable cases of extrabronchial oat-cell carcinoma have been published in the English literature, and the validity of some of these has recently been called into question by Rosen et al (1975).

McKeown (1952) reported two cases of oat-cell carcinoma in the oesophagus, and Corrin et al (1973) described one in the pancreas with ectopic ACTH production. One other such tumour, in which neurosecretory granules were demonstrated electron microscopically, was recently noted in the larynx (Benisch et al, 1975).

Ectopic ACTH production was also found in two oat-cell carcinomas of the oesophagus reported in Japan (Taniguchi et al, 1973). The light microscopy of two other primary oesophageal tumours was described as resembling oat-cell carcinoma (Rosen $e t$ al, 1975; Turnbull et al, 1973) but epidermoid differentiation in one of these (Rosen et al, 1975) was interpreted as indicating an origin from squamous epithelium, at the same time calling into question the existence of the entity of oat-cell carcinoma of the oesophagus. We describe here another case of carcinoma of the oesophagus with an oat-cell pattern and demonstrate its true nature.

\section{Case report}

A 73-year-old woman presented with a four-month history of pain in the interscapular region on swallowing. This had progressed, and regurgitation of food was accompanied by the loss of $4 \mathbf{~ k g}$ in three months. A barium swallow revealed irregularity of the oesophageal mucosa in the lower third of the

Received for publication 5 April 1976 oesophagus. Oesophagoscopy demonstrated a stric- 옥 ture at that site, and examination of a biopsy of this $\vec{\nabla}$ revealed a poorly differentiated squamous carci- $\mathbb{D}$ noma. The gastro-oesophageal junction appeared normal. The lower third of the oesophagus was excised, at which time tumour deposits were noted in $\stackrel{\mathbb{C}}{\mathrm{C}}$ the liver. The patient bled profusely postoperatively $\vec{\theta}$ and resuscitation and haemostatic procedures wex unsuccessful.

\section{PATHOLOGY}

At necropsy a perforation of the oesophagus posteriorly was found associated with considerable haemorrhage. No residual local tumour was found and no primary, metastatic or invasive tumour was present in the lungs. The hilar and mediastinal nodes were also free of tumour. The surgical specimen consisted of $9 \mathrm{~cm}$ of oesophagus and proximal stomach and contained a tumour $4.5 \mathrm{~cm}$ in length (fig 1). This was ulcerating, invasive, and stenotic, and in its proximal part, between the upper two arrows in 3 . fig 1, appeared pale waxy brown and uniform on cut $\delta$ surface whereas in its lower part, between the lower two arrows in fig 1, it was paler and more friable. Two large metastases in lymph nodes showed a corresponding contrast in the appearance of their cut surfaces. Fixation was in $10 \%$ formalin.

Microscopically these areas correspond to two $\sigma$ patterns in the tumour which are continuousand show $N$ no intervening transitional pattern (fig 2). The $\underset{\omega}{N}$ proximal part of the tumour has the pattern of an oat-cell carcinoma with trabeculae of small angular

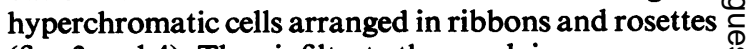
(figs 3 and 4). They infiltrate the overlying squamous $\stackrel{?}{?}$ epithelium and approximately half-way through the smooth muscle coat. Areas of necrosis are scanty $\overrightarrow{0}$ and no Feulgen positive deposits are noted in vessel $\mathbb{D}$ walls (Azzopardi, 1959). The Bodian silver impreg- $\frac{\vec{D}}{\mathrm{D}}$ 


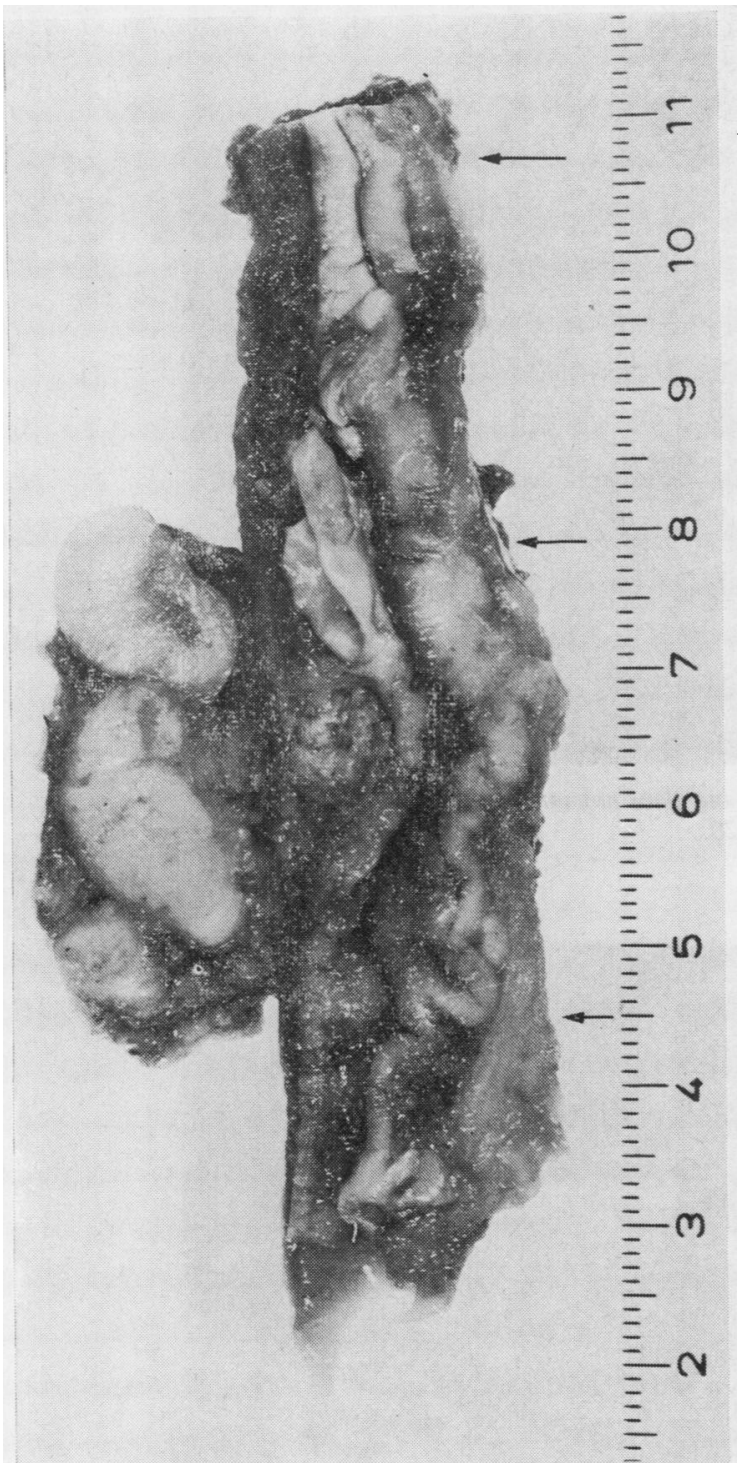

Fig 1 The dissected surgical specimen, showing between the upper two arrows the part of the tumour with an oat-cell pattern and between the lower two, that with a squamous pattern. The lymph nodes on the left contain metastatic carcinoma.

nation for argyrophilic cells was considered negative. After post fixation in $1 \%$ phosphate buffered osmium tetroxide and embedding in Epon, sections were stained with alcoholic uranyl acetate and Reynold's lead citrate and examined with an AEI EM 801 microscope. Then neurosecretory granules, described in oat-cell carcinomas by Bensch et al (1968), were demonstrated. These granules, present in about $3 \%$ of the cells, range in size from 800 to $4500 \AA$ and show a well-defined limiting membrane. When present they are sparse in some cells and densely packed in others (figs 5 and 6). No tonofilaments were found in this part of the tumour. The lower part of the stricture was formed by a squamous carcinoma, well differentiated in some areas (fig 2) but mostly poorly differentiated. Desmosomes and tonofilaments are clearly visible ultrastructurally in tissue from this part of the tumour. Four para-oesophageal lymph nodes contain metastatic deposits. Two of these have an oat-cell pattern, one is squamous, and the fourth contains both oat-cell and squamous carcinoma, though apparently as separate deposits without any indication of transition.

\section{Discussion}

The tumour we have described showed the histological patterns of ribbons and rosettes, the typical cytology and neurosecretory granules, all characteristic of oat-cell carcinoma.

We regard the two cases of McKeown (1952) also as genuine oat-cell carcinomas because they showed typical histological features including, in case 2 , the DNA vascular deposits described by Azzopardi (1959).

The two Japanese cases (Taniguchi et al, 1973) were reported to have an ectopic production of ACTH which is also a well-recognized complication of oat-cell carcinoma but is not a feature of squamous carcinoma.

We think these five cases provide enough evidence to support the concept that oat-cell carcinoma is a rare type of primary oesophageal carcinoma. Two other probable cases have been reported (Turnbull et al, 1973; Rosen et al, 1975). In our case, all the criteria demanded by Rosen et al (1975), who expressed some scepticism about the entity, are fulfilled; this includes the ultrastructural demonstration of neurosecretory granules.

The origin of such carcinomas is questionable. McKeown (1952) regarded the possible source as the persistent islands of the original embryonic ciliated columnar entodermal epithelium (Raeburn, 1951). There is little evidence to support this view. Another possible explanation is an origin from the argyrophil cells of the oesophageal mucosa, recently described by Tateishi et al (1974). This would be analogous to the oat-cell carcinomas of the bronchus which are considered to be derived from the argyrophil cells distributed along the bronchi and bronchioles (Tateishi, 1973).

Our case also had a squamous carcinomatous component but this finding is not unique. McKeown's second case consisted of a squamous 


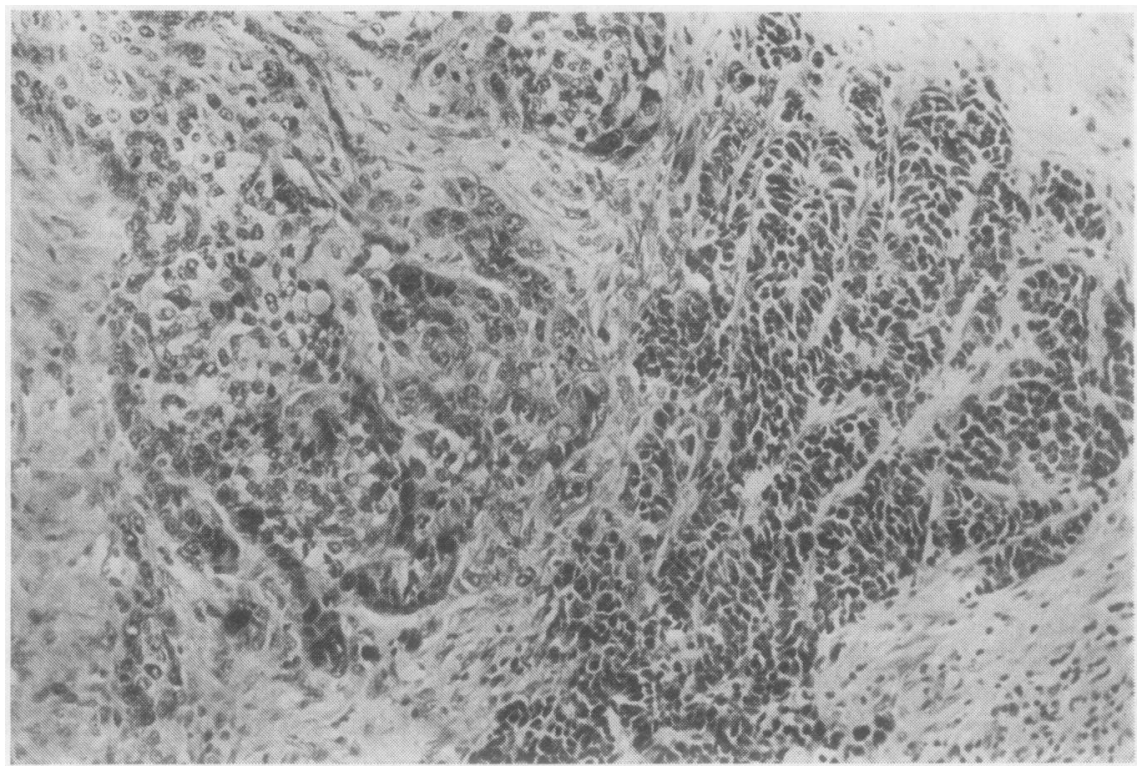

Fig 2 The oat-cell pattern on the right abutts but does not intermingle with the squamous carcinoma on the left. $H$ and $E \times 120$.

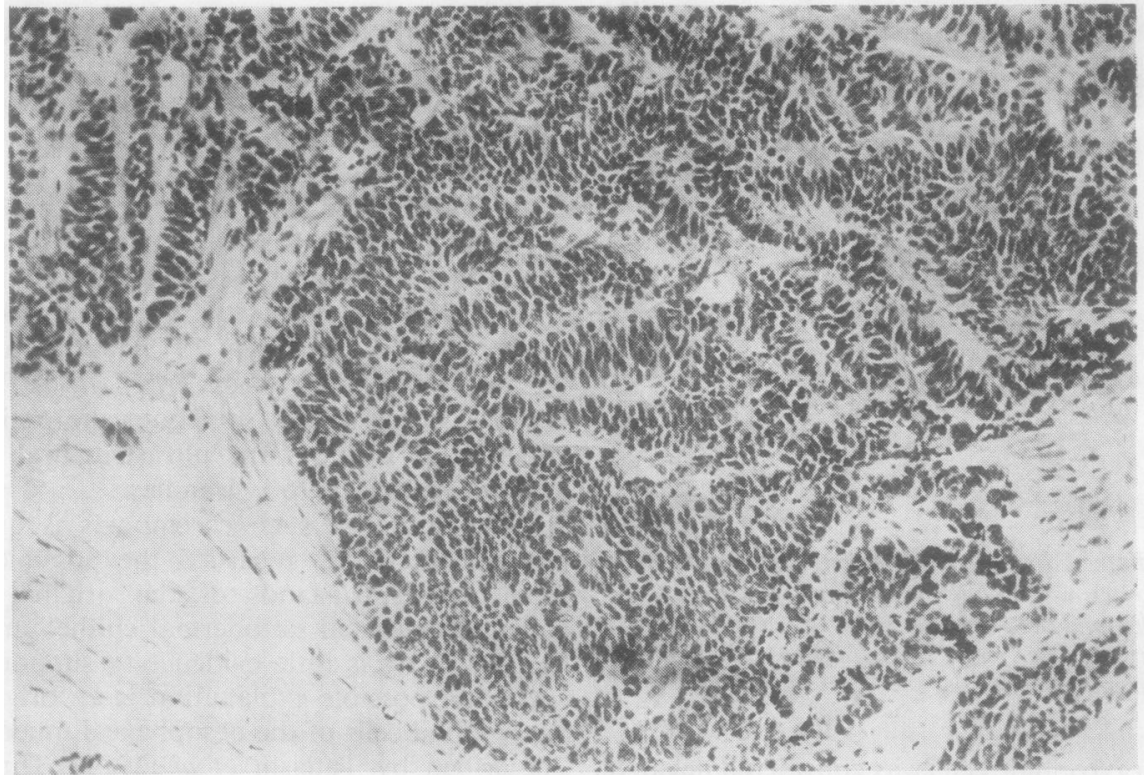

Fig 3 The oat-cell carcinoma showing the typical ribbons and rosettes of hyperchromatic cells invading the subepithelial tissues of the oesophagus. $H$ and $E \times 100$.

carcinoma intermingled with an oat-cell carcinoma, and one case of the series reported by Azzopardi (1959) showed the same features. Furthermore, in the oesophagus it is not exceptional to have carci- nomas formed by two components, as reported by Dodge (1961), who described four cases with features of both squamous and adenocarcinoma.

The precise histogenetic relationship of the two 


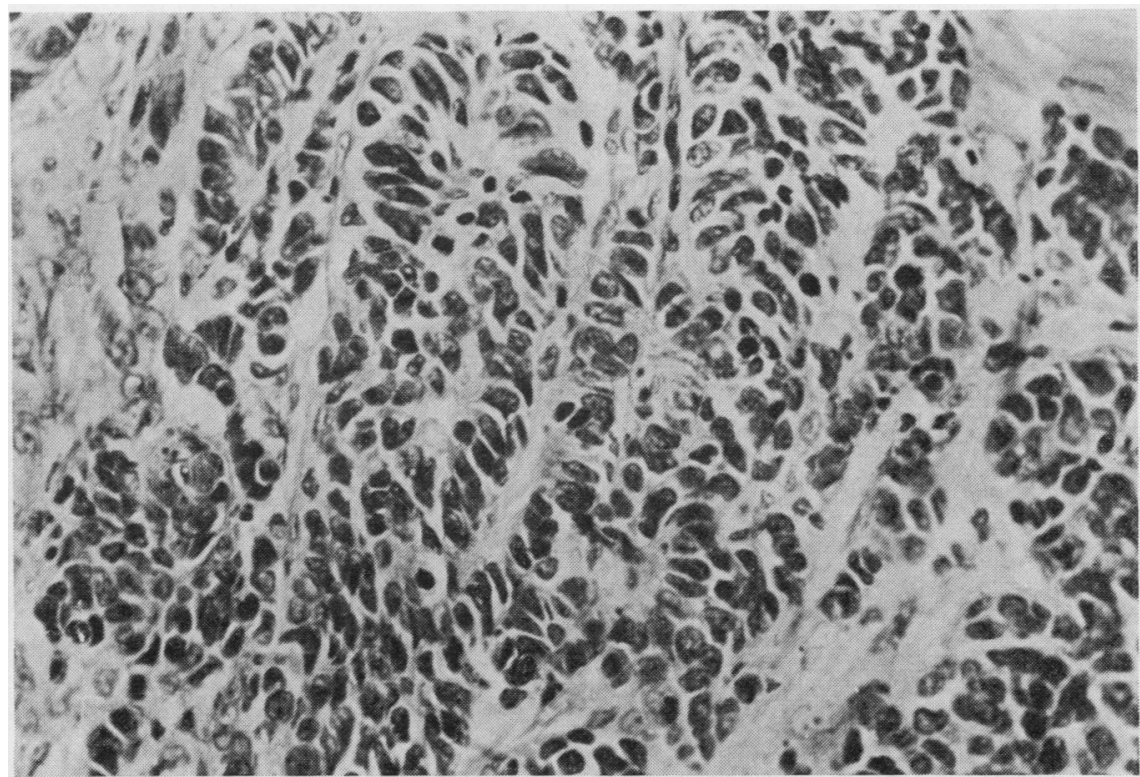

Fig 4 The angular hyperchromatic nuclei in the trabeculae of cells of the oat-cell carcinoma. $H$ and $E \times 250$.

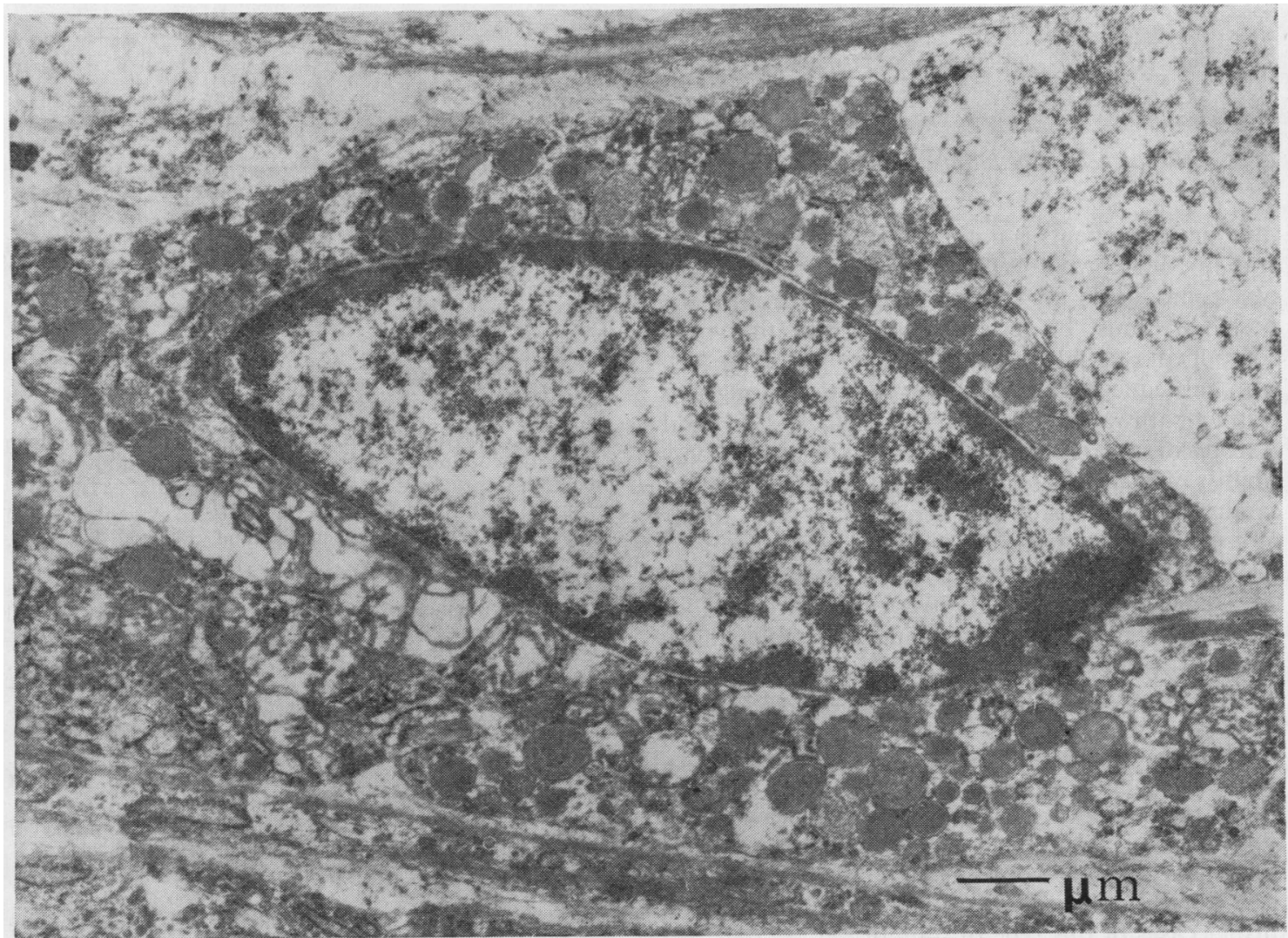

Fig 5 Electron micrograph of cell containing neurosecretory granules in oat-cell carcinoma. $\times 10400$. 


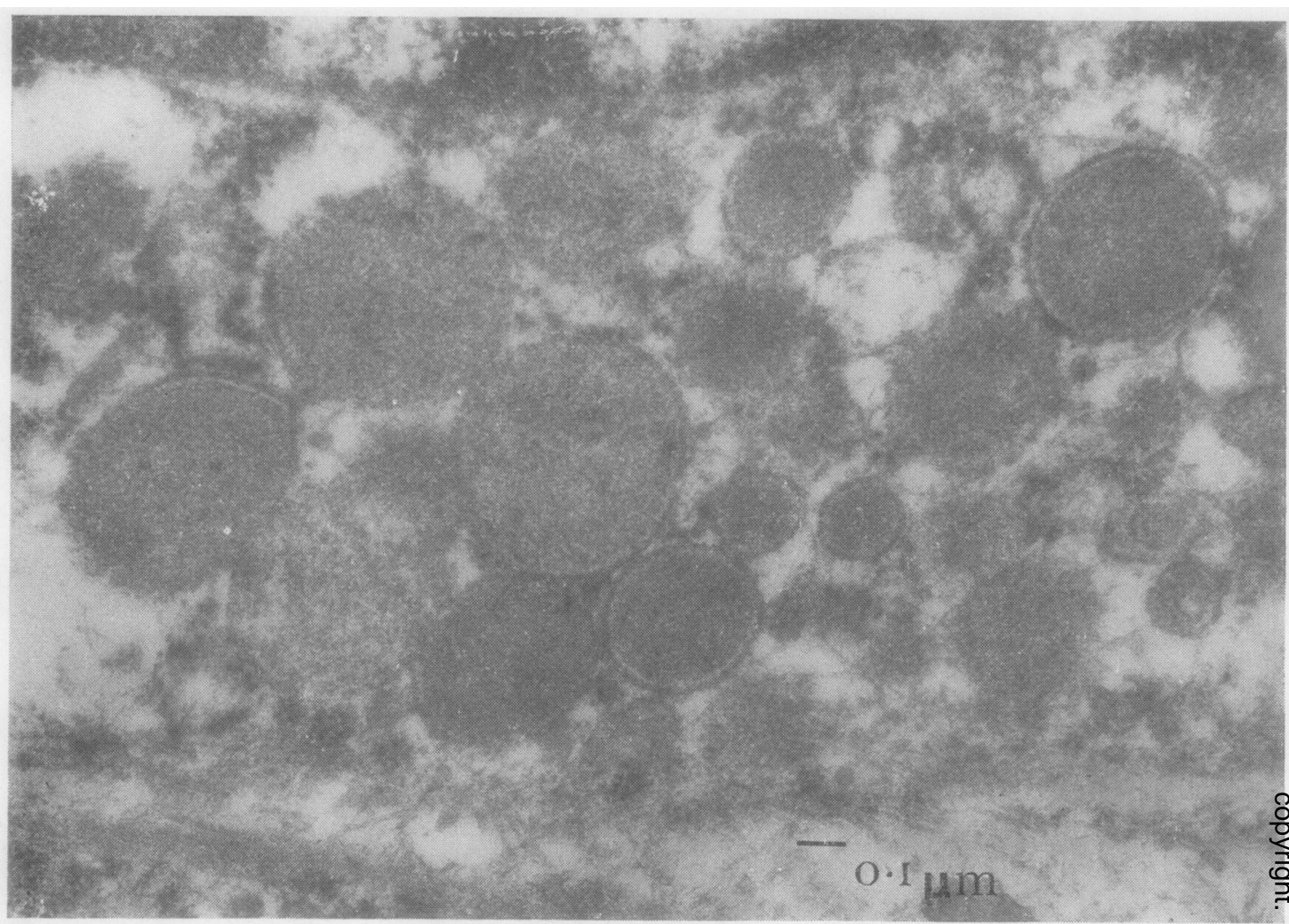

Fig 6 Ultrastructural detail of cytoplasm in oat-cell carcinoma cell showing neurosecretory granules. $\times 56500$.

tumour components is not clear. In the present case, and in McKeown's (1952) to a major degree, the two components are closely related. Therefore the possibility must be seriously considered that both components could be derived from the same cell with subsequent divergent differentiation along two distinct pathways. Azzopardi and Pollock (1963) and Azzopardi and Evans (1971) considered the possibility of a divergent differentiation in the adenocarcinomas of the stomach and prostate. It is therefore possible that oat-cell carcinoma and squamous carcinoma of the oesophagus could be derived from the same cell of origin with divergent differentiation. This would result in oat-cell and squamous carcinoma remaining distinct or coalescing in varying degrees or even showing transitions between the two tumours. But clearly we cannot, at this stage, exclude dual origin from argyrophil cells or precursors on the one hand and keratinocytes on the other.

The main purpose of this paper is to draw attention to the existence of a rare primary oat-cell carcinoma of the oesophagus. The histogenesis will need to be considered in the light of the discovery of further cases of this type of tumour.
We are very grateful to Professors J. G. Azzopardi $\stackrel{2}{\Rightarrow}$ and A. M. Mancini for their advice.

\section{References}

Azzopardi, J. G. (1959). Oat-cell carcinoma of the bronchus. J. Path. Bact., 78, 513-519.

Azzopardi, J. G. and Evans, D. J. (1971). Argentaffin cells in prostatic carcinoma: differentiation from lipofuscin and melanin in prostatic epithelium. J. Path., 104, 247-251.

Azzopardi, J. G. and Pollock, D. J. (1963). Argentaffin and argyrophil cells in gastric carcinoma. J. Path. Bact., 86, 응 443-451.

Benisch, B. M., Tawfik, B., and Breitenbach, E. E. (1975) Primary oat-cell carcinoma of the larynx: an ultrastructural study. Cancer (Philad.), 36, 145-148.

Bensch, K. G., Corrin, B., Pariente, R., and Spencer, H. (1968). Oat-cell carcinoma of the lung: its origin and rela- $\mathrm{N}$ tionship to bronchial carcinoid. Cancer (Philad.), 22, 1163- ㅇ 1172.

Corrin, B., Gilby, E. D., Jones, N. F., and Patrick, J. (1973). Oat-cell carcinoma of the pancreas with ectopic ACTH secretion. Cancer (Philad.), 31, 1523-1527.

Dodge, O. G. (1961). Gastro-oesophageal carcinoma of mixed histological type. J. Path. Bact., 81, 459-471.

McKeown, F. (1952). Oat-cell carcinoma of the oesophagus. $\square$ J. Path. Bact., 64, 889-891.

Raeburn, C. (1951). Columnar ciliated epithelium in the $\stackrel{+}{\mathbb{P}}$ adult oesophagus. J. Path. Bact., 63, 157-158. 
Rosen, Y., Moon, S., and Kim, B. (1975). Small cell epidermoid carcinoma of the oesophagus: an oat-cell-like carcinoma. Cancer (Philad.), 36, 1042-1049.

Taniguchi, K., Tateishi, R., and Horai, T. (1973). ACTHproducing oat-cell carcinoma of the oesophagus. Report of two cases. Saishin-Igaku, 28, 1834-1838.

Tateishi, R. (1973). Distribution of argyrophil cells in adult human lungs. Arch. Path., 96, 198-202.

Tateishi, R., Taniguchi, H., Wada, A., Horai, T., and Taniguchi, K. (1974). Argyrophil cells and melanocytes in oesophageal mucosa. Arch. Path., 98, 87-89.

Turnbull, A. D., Rosen, P., Goodner, J. T., and Beattie, E. J. (1973). Primary malignant tumors of the oesophagus other than typical epidermoid carcinoma. Ann. thorac. Surg., 15, 463-473.

\section{Addendum}

A second very similar case of oat-cell carcinoma of the oesophagus has presented since this paper was submitted. A 65-year-old woman with a threemonth history of dysphagia had a gastro-oesophagectomy for a constricting oesophageal tumour. The ulcerated tumour, $3.8 \mathrm{~cm}$ in length and situated $5 \mathrm{~cm}$ above the gastro-oesophageal junction, had mainly the pattern of oat-cell carcinoma but included a small area of well-differentiated squamous carcinoma. The tumour had extended only half way through the muscle coats but metastases of oat-cell carcinoma were present in three para oesophageal lymph nodes. There is no evidence of a lung tumour. Electron microscopy again revealed neurosecretory granules in a small proportion of the cells from the area of tumour with the pattern of an oat-cell carcinoma. 